\title{
Asphalt Concrete Overlay Optimization Based on Pavement Performance Models
}

\author{
Jan Mikolaj, Lubos Remek, and Marian Macula \\ University of Žilina, Žilina, Slovakia \\ Correspondence should be addressed to Lubos Remek; lubos.remek@fstav.uniza.sk
}

Received 14 April 2017; Revised 22 June 2017; Accepted 27 July 2017; Published 14 September 2017

Academic Editor: Hainian Wang

Copyright (C) 2017 Jan Mikolaj et al. This is an open access article distributed under the Creative Commons Attribution License, which permits unrestricted use, distribution, and reproduction in any medium, provided the original work is properly cited.

The life cycle length of pavement with asphalt concrete material (ACM) surfacing is significantly influenced, in addition to transport loading and climatic conditions, by design method and rehabilitation timing. Appropriate overlay thickness calculation and estimation of optimal rehabilitation time are crucial to maximizing life cycle length and, concurrently, reducing road administration costs and road user costs. This article describes a comprehensive method of ACM rehabilitation design. For optimization of life cycle cost analysis (LCCA) based design, mathematical analytical solution in combination with experimental verification of physical, mechanical, and fatigue characteristics is utilized. Pavement performance, that is, functions mathematically describing pavement's degradation characteristics of operational capability, is represented by longitudinal and transverse unevenness; these are used to describe relations between traffic loading and pavement's bearing capacity on 1:1 scale. Optimizing of rehabilitation plan is carried out by making a cost benefit analysis (CBA) for several rehabilitation scenarios in which different rehabilitation timing produces different capital cost requirements and social benefits. Rehabilitation scenarios differ in technology, the design of which needs to be mathematically optimized, and timing of rehabilitation execution. This article includes a case study for the sake of illustration of practical results and verification of applicability of used methodology.

\section{Introduction}

Design optimization calculation method for ACM pavements is a complex method using analytical-experimental methods for calculating of overlay thickness and resulting life cycle extension, in addition to general deterministic pavement performance modelling and CBA. To calculate the required ACM overlay thickness, it is imperative to know the mathematical model and numerical solution of layered elastic half-space [1, 2]. Layered elastic half-space defines stress and deformation in the pavement construction by using the strength characteristics of surfacing ACM materials and underlying sublayers. Based on traffic loading and climatic conditions of particular pavement, the results allow residual service life calculation of the pavement and possible overlay thickness for achieving service life extension of another 20 years [3-5]. The crucial parameter for the pavement's service life calculation is the fatigue characteristics of ACM materials in the surfacing. Because ACM materials differ in asphalt type, aggregate, additives, and their ratio, the fatigue properties need to be determined experimentally. The dynamic modulus (complex modulus) method [6-8] was used throughout research efforts $[9,10]$, this article of which is part of the dissemination activities. However, the calculation of the necessary overlay thickness based on the theory of elasticity, that is, plasticity, needs to be supported by evaluation of longitudinal and transversal unevenness. This unevenness arises as a result of permanent deformation of pavement which is no longer in a flexible state, which can be derived again only on the basis of experimental methods [11-16]. For this reason, experimental accelerated pavement testing (APT) facility [17] was designed to provide results, on which such derivations can be made in combination with long term pavement performance monitoring and laboratory material testing. It is a patent protected facility, traffic load and the pavement construction are designed on a 1:1 scale, and the facility uses several innovative concepts for ACM surfacing material testing. Comprehensive sensor suite is embedded within the pavement, especially in the ACM layers, to measure strains temperature and humidity. Deformations 


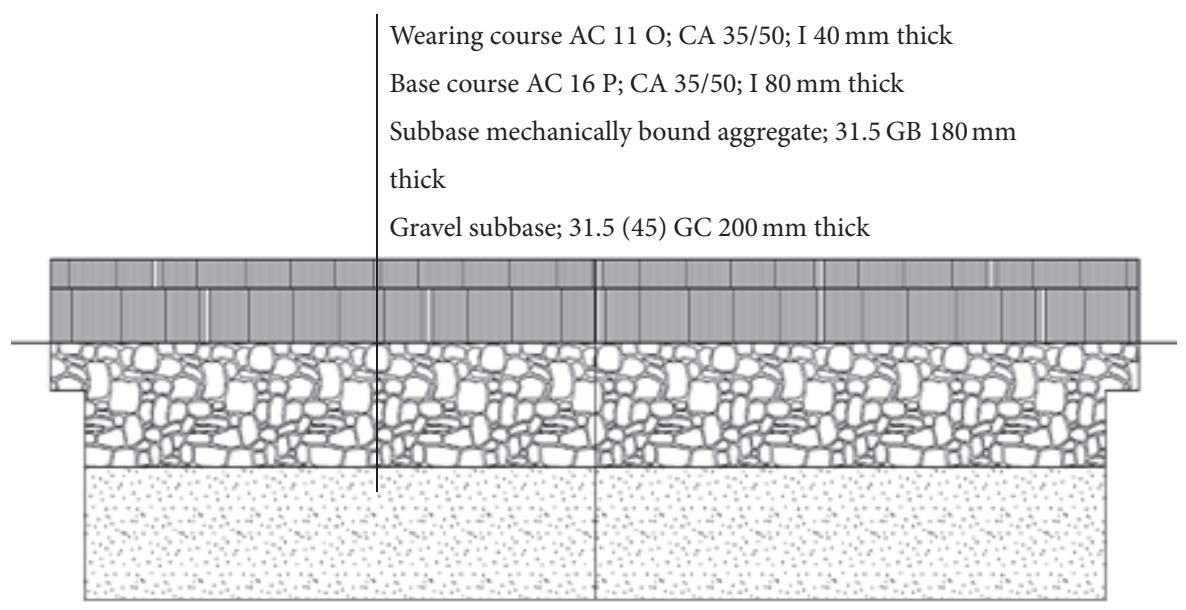

FIgURE 1: Pavement structure.

can be derived since the ACM materials characteristics were tested in laboratory conditions. The pavement performance represented by longitudinal and transversal unevenness is periodically recorded as a dense point mesh using Lidar scanners and evaluated via their software suite. This enables creating equations describing loss of pavement evenness in relation to loading volume. Due to the fact that the device is already in full operation for some time, first equations can be published; these however can change slightly in the future as the experiment goes on. Long term pavement performance monitoring is performed by the Slovak road administration. The APT results can be thus compared and verified on roads with similar structure to the experimental pavement [18]. In this article, we present the results verified by 15 years of data collection on pavements in operation. The results obtained by the APT serve foremost to define the critical state in which the ACM has reached the limit state of failure and must be removed or recycled [19]. In addition, the pavement deformation model serves as a base to calculate vehicle operating costs in concordance with the World Bank's approach "Highway and Development and Management" (HDM). The shape of pavement degradation is thus pivotal in the CBA as a difference in shapes of pavement degradation functions denotes different vehicle operation cost flows during the pavement's life cycle [20-24]. Application of comprehensive method of rehabilitation designing, including physicomechanical properties, fatigue characteristics, strain calculation, deformation, and overlay thickness as well as CBA, is created for particular pavement type or pavement class.

\section{Experimental Pavement Model}

Because of the application of complex rehabilitation methodology needs to be performed on particular pavement type, experimental road section was designed and constructed. The surfacing is composed of ACM prescribed by technical standards to ensure quality and match with real life pavements. The base course in a mechanically bound aggregate, subbase, is a compressed gravel layer; the earth works are simulated by a rubber layer on concrete with the equivalent modulus of well compressed subsoil. The pavement was designed according to the standard dimensioning methodology [25] for a minimum level of traffic load of $2.10^{6}$ design axles. The entire pavement was subsequently built in the laboratories of the Department of Construction Management at the University of Žilina. The experimental model of pavement construction is shown in Figure 1.

Pavement structure layers are designed from generic materials defined in national standards. Table 1 contains material characteristics ascertained by the initial physical measurement of surfacing materials.

\section{Design of Rehabilitation Variants}

Calculation of pavement life cycle is possible only on the basis of pavement design method, that is, structural design, and overlay design method.

3.1. Structural Design. The calculation of required overlay thickness is based on the analytical-experimental methods. Pavement construction including ACM surfacing is to be considered as a multilayer system on a flexible subsoil. Each layer, including overlay layers, is characterized by its thickness, modulus of elasticity, and Poisson numbers. The calculated stress $\sigma_{r i}$ is generated by repeated axle load (passing of freight vehicles) which is represented as an effect of the design axle load equivalent of 10 tonnes $(2 P=100 \mathrm{kN})$. Pavement's bearing capacity constitutes the baseline for operational performance estimation in critical layer of the pavement structure and thus in the whole structure of the pavement. Once the bearing capacity of this critical layer is depleted by carrying traffic load, fatigue tear emerges, which gradually copies itself into the rest of the layers. This relation is expressed in the design methodology by comparison of the maximal computed strain at the bottom of the ACM surfacing layer $\sigma_{r}$ and the bending strain resiliency of ACM reduced by the fatigue coefficient $S_{N}(X)$.

$$
\mathrm{SV} \geq \frac{\sigma_{r i}}{S_{N} * R_{i}}
$$


TABLE 1: Material characteristics of pavement layers.

\begin{tabular}{|c|c|c|c|c|}
\hline Layer & Complex modulus & Resistance & Poisson number & Layer thickness \\
\hline $\mathrm{AC} 11 \mathrm{O}$ & 10,891 & $3.2 \mathrm{MPa}$ & 0.33 & $40 \mathrm{~mm}$ \\
\hline AC $16 \mathrm{P}$ & 8,317 & $2.4 \mathrm{MPa}$ & 0.33 & $80 \mathrm{~mm}$ \\
\hline MBA, 31,5 GB & 586 & $0.1 \mathrm{MPa}$ & 0.30 & $180 \mathrm{~mm}$ \\
\hline Gravel subbase, 31,5 & 365 & $0.07 \mathrm{MPa}$ & 0.30 & $200 \mathrm{~mm}$ \\
\hline Subgrade & 100 & - & 0.35 & - \\
\hline
\end{tabular}

where

SV is structural value (utilization index),

$\sigma_{r i}$ is radial stress,

$R_{i}$ is resistance to radial stress,

$S_{N}$ is fatigue characteristic.

Fatigue characteristics are used in the assessment of pavement resilience against repeated loading. Test temperature for the endurance test is $10^{\circ} \mathrm{C}$ and the frequency of cyclic loading is $25 \mathrm{~Hz}$. The test is carried out at a constant bend of the test sample during the test. Fatigue tests were carried out according to the European standard [6]. Results of the fatigue test are in the form of a Wöhler diagram.

$$
\log \varepsilon_{0 j}=a_{j}+b \log N,
$$

where

$\varepsilon_{0 j}$ is maximum amplitude of proportional deformation in the test conditions at the beginning of the measurement,

$a_{j}, b$ are parameters measured during the fatigue tests with the stress lines coefficient in the range of $N$,

$N$ is the number of load repetitions.

The characteristics of the fatigue that are in the equation are the average size of deformation derived from stress lines derived after $10^{6}$ loading cycles in microstrain $(\mu \mathrm{m} / \mathrm{m})$.

$$
\log \left(\frac{\varepsilon_{6}}{10^{6}}\right)=a_{j}+6 b,
$$

where

$$
a_{j}, b \text { are fatigue parameters, }
$$

$\varepsilon_{6}$ is average deformation derived from fatigue curve after $10^{6}$ loading cycles in microstrain $[\mu \mathrm{m} / \mathrm{m}]$.

The number of loads corresponding to the initial deformation in the test sample under specified conditions can be ascertained as

$$
\begin{aligned}
& N=10^{6}\left(\frac{\varepsilon_{6}}{\varepsilon_{0}}\right)^{B} \\
& B=-\frac{1}{b},
\end{aligned}
$$

where

$B$ is the fatigue characteristics in the range of 3 to 10.
TABLE 2: Values of fatigue parameters for mix AC $11 \mathrm{O}$.

\begin{tabular}{lcccc}
\hline Parameter & $a$ & $1 / b$ & $\varepsilon_{6} \times 10^{-6}$ & $r^{2}$ \\
\hline Fatigue parameters & -15.0754 & -0.1927 & 86.77 & 0.7871 \\
\hline
\end{tabular}

The results of research carried out in the ambit of fatigue characteristics are presented in Figure 2 and Table 2.

The life cycle of ACM in the pavement construction can be expressed through (1), on the basis of the strain calculation in pavement construction, resiliency, and fatigue coefficient. The SV value must be less than 1 , so that the value of the radial strain does not exceed the value of resiliency reduced by the fatigue characteristics. If the value is exceeded, the ACM is at the end of its life and failures appear.

Obviously, during the service life, as the surfacing wears down, elastic modulus of ACM layers diminishes which results in surfacing resiliency loss. Calculation of elastic modulus decrease can be based on experimental fatigue testing. The results for materials used in this case study were published in [9]. Radial strain and resiliency loss can be calculated by means of mathematical elastic multilayer halfspace model [26]. Table 3 summarizes measured loss of elastic modulus and calculated radial strain and resiliency decrease.

The shape of calculated strain in relation to elastic modulus decrease and resiliency loss is shown in Figure 3. When the drop in strain levels on the bottom edge of the ACM reaches the resiliency, the ACM fails and tear is created.

The calculation of capacity utilization coefficient Sv based on (1) for this case study, that is, for ascertained material elastic modulus and fatigue, is shown in Figure 4. Calculation results, attained according to the herein described approach, have shown that pavement with these particular ACM layers has life cycle length of $2 e^{6}$ design axle load repetitions without any rehabilitation. This particular pavement type is designed for load class with expected 275 design axle load repetitions daily; this equals about $1 e^{5}$ design axle load repetitions per year, which in turn means that the bearing capacity will be depleted after 20 years of operation.

3.2. Overlay Design. The life cycle represents number of load repetitions acting on ACM layer up to the state of a failure. As stated in Section 1 of this article, several rehabilitation scenarios need to be identified for the LCCA optimization of any given ACM. These scenarios differ in rehabilitation timing and overlay structure design which changes in time; that is, thickness is increasing as the bearing capacity diminishes; later rehabilitation leads to thicker overlays. Important aspect of overlay structure design is that mechanical properties of existing ACM layers are reduced (degraded), as was explained 
TABLE 3: Elastic modulus, radial strain, and resiliency decrease in relation to traffic loading.

\begin{tabular}{lcccccc}
\hline$N_{i}$ repetitions & 0 & $0.4 \times 10^{6}$ & $0.8 \times 10^{6}$ & $1.2 \times 10^{6}$ & $1.6 \times 10^{6}$ & $2.0 \times 10^{6}$ \\
\hline AC 11 O $(\mathrm{MPa})$ & 10,891 & 5,998 & 5,759 & 5,620 & 5,521 & 4,45 \\
AC 16 P $(\mathrm{MPa})$ & 8,317 & 4,580 & 4,398 & 4,291 & 4,216 \\
Radial strain $(\mathrm{MPa})$ & 0.978132 & 0.634328 & 0.613133 & 0.600401 & 0.591348 \\
Resiliency $(\mathrm{MPa})$ & 0.92400 & 0.769512 & 0.690040 & 0.643552 & 0.610568 & 0.584278 \\
\hline
\end{tabular}

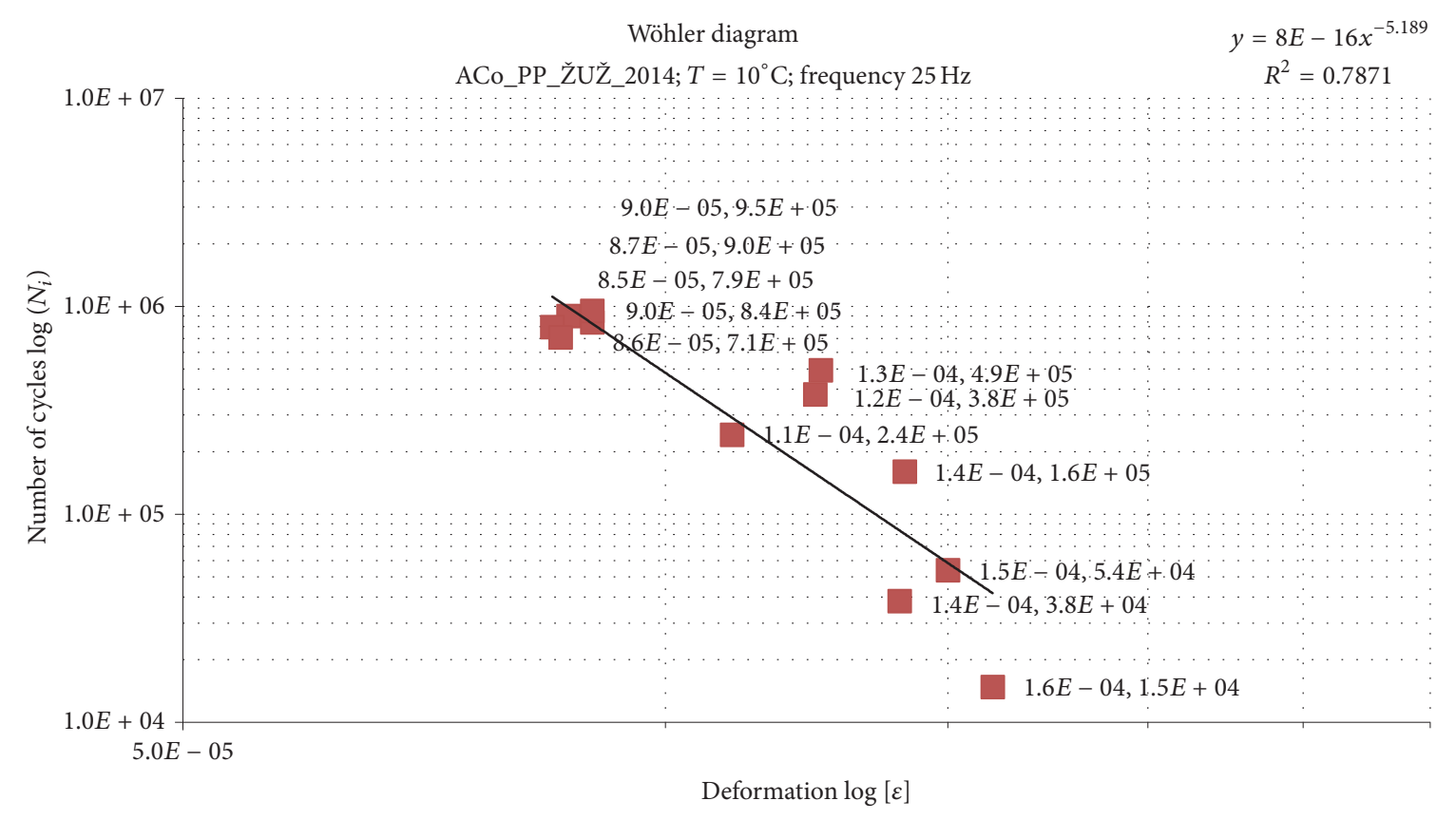

FIGURE 2: Wöhler diagram.

in Section 3.1, while the overlay ACM layer is always expected to have the inherent maximal properties. It is important to point out that, from technological as well as ecological point of view, ACM layers can be recycled to recoup the properties of a new material.

In terms of overlay design method, the rehabilitation entails increase in elastic modulus of ACM surfacing and by adjusted thickness of the surfacing layer. In Figure 5, four rehabilitation scenarios are shown in four different life cycle periods including scenario of rehabilitation at the end of the predicted life cycle. Overlay design thickness for these four scenarios was calculated based on radial strain in ACM layer. Overlay is designed to replete the lost bearing capacity, thus expanding the ACM lifecycle by additional 20 years, that is, returning the pavement to its original pristine state. Computed results for these four scenarios including elasticity modulus in rehabilitation year and radial strains before and after rehabilitation are shown in Table 4.

The development of radial strains in the pavement construction is shown in Figure 5.
Overlay designs and their timing and life cycle extension are shown in Figure 6.

\section{Pavement Performance Models}

In order to ascertain rehabilitation timing and identify prudent rehabilitation scenarios, pavement performance degradation should be taken into account. If the rehabilitation is performed too early, it is usually inefficient; delayed rehabilitation may lead to loss of pavement's operational serviceability $[13,18,27]$. Pavement performance models are represented by mathematical equations describing accruement of longitudinal and transversal unevenness under traffic load. Accelerated pavement testing in combination with long term performance monitoring is a preferred approach to ascertain these equations. It is presumed that the pavement is repaired only once serviceability of the original pavement is lost but before the operational capacity is reached. Overlay, where thickness is calculated according to real state of the pavement, restores its original properties, that is, new pavement properties. Overlay can be performed by removing (or recycling) 
TABLE 4: Radial strains prior to and after overlay.

\begin{tabular}{lcccccccc}
\hline Year & 5 & 10 & 15 & 20 & 25 & 30 & 35 & 40 \\
\hline ACM layer thickness increase (mm) & $36^{*}$ & $52^{*}$ & $62^{*}$ & $71^{*}$ & - & - & - & - \\
AC 11-overlay E (MPa) & 10891 & 10891 & 1089 & 1089 & 5445 & 5445 & 5445 & 5445 \\
AC 11 O E (MPa) & 5945 & 5682 & 5551 & 5445 & 5354 & 5304 & 5248 & 5205 \\
AC 16 P E (MPa) & 4540 & 4339 & 4239 & 4158 & 4088 & 4051 & 4008 & 3975 \\
Strain prior to rehabilitation (Mpa) & 0,751838 & 0,664456 & 0,620544 & 0,584984 & 0,48615 & 0,4465 & 0,42012 & 0,40146 \\
Strain after rehabilitation (Mpa) & 0,508571 & 0,464004 & 0,429907 & 0,40146 & 0,477312 & 0,428528 & 0,404145 & 0,382118 \\
\hline
\end{tabular}

* In this theoretical calculation, the overlay thickness is computed exactly to return the pavement to its original bearing capacity; in the field, for practical reasons, the thickness would be rounded up to a whole number.

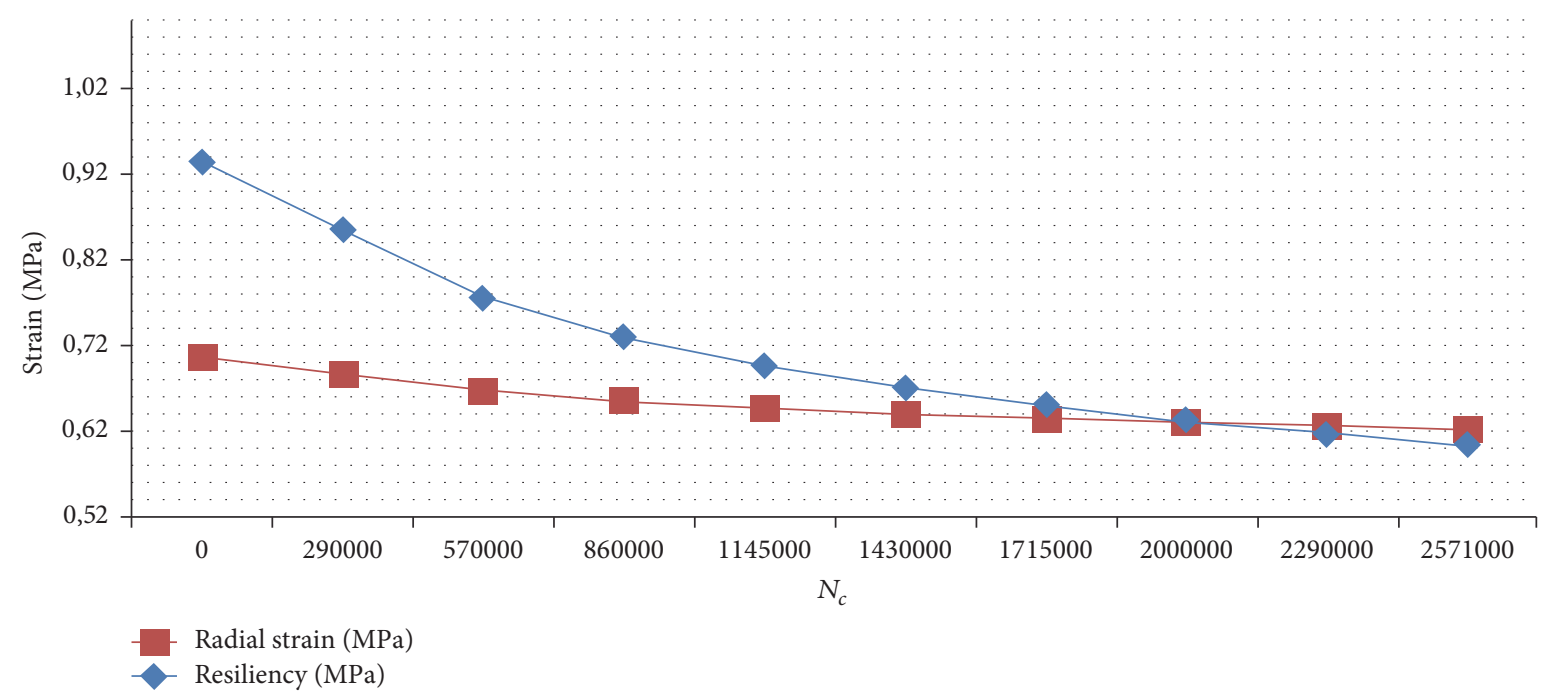

FIGURE 3: Relationship between stress in ACM depending on repeated loading and decrease of ACM strength resiliency depending on the fatigue trend function.

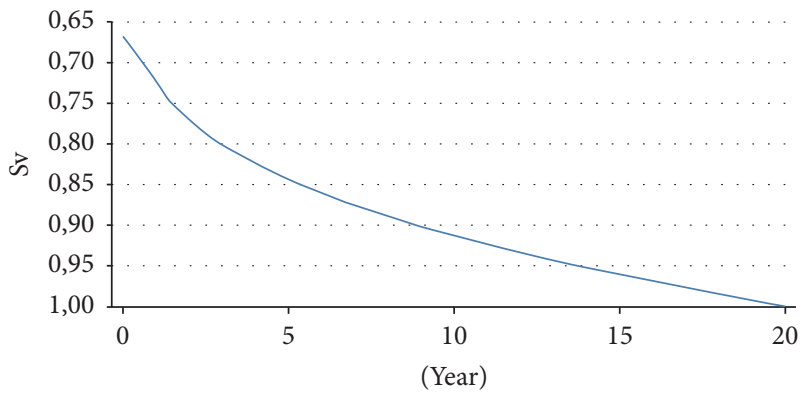

FIGURE 4: Increase of capacity utilization coefficient Sv.

part of or complete surfacing layer. For this reason it is not possible to distinguish between new and recycled pavement. The same mathematical equations are used for both cases.

4.1. Accelerated Pavement Testing. The general principle of APT is simulation of real life traffic loading on real life pavement. This traffic load is preferably the design axle load, for which the pavement is designed. In this case, it is $50 \mathrm{kN}$. The loading unit is driven along a leading rail; it is powered by an electromotor. Acceleration, deceleration, and top speed are

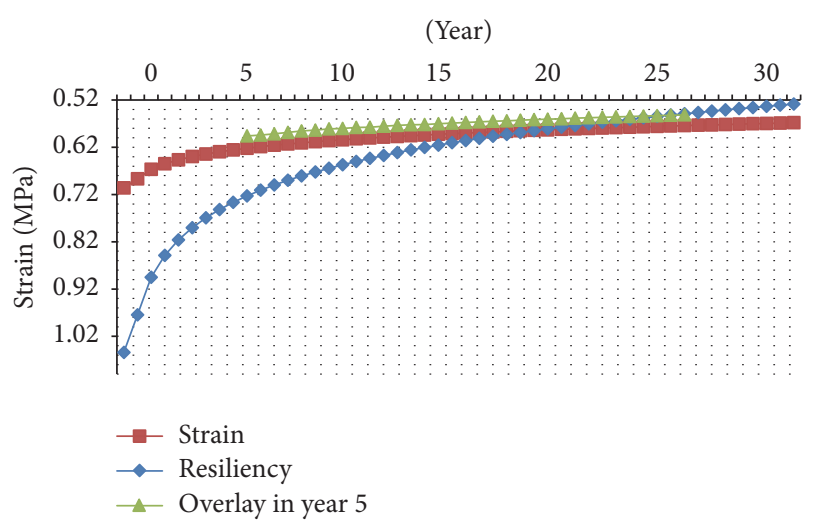

FIGURE 5: Radial strains before and after rehabilitation.

adjustable within constraints of the pavement length. Radial strains at the bottom edge of surfacing arise as a combination of surfacing deflection under the loading unit and acceleration and deceleration forces on the tire-pavement contact area. APT facility parameters are listed in Tables 5 and 6 .

The loading unit runs the pavement section in both directions. In addition to weight of the loading unit itself, additional weight is loaded on the unit to reach the required 


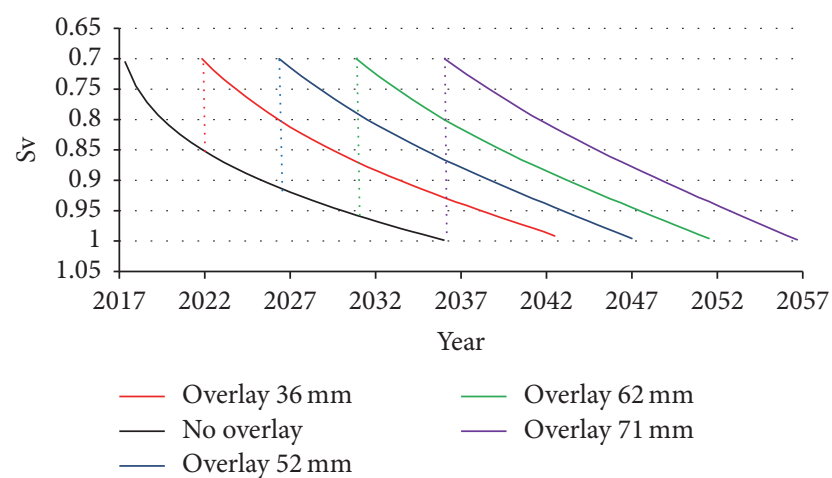

FIGURE 6: Overlay design and timing of four rehabilitation scenarios: Sv and life cycle relation.

TABLE 5: APT facility dimensions.

\begin{tabular}{lc}
\hline \multicolumn{2}{c}{ Technical parameters } \\
\hline Length & $9,042 \mathrm{~mm}$ \\
Width & $5,178 \mathrm{~mm}$ \\
Width with protective fence & $6,000 \mathrm{~mm}$ \\
Height & $2,452 \mathrm{~mm}$ \\
\hline
\end{tabular}

$50 \mathrm{kN}$ loading. Shape of acceleration curve, constant speed, and deceleration curve is set up before the loading session. If valid, the loading unit will be driven at the desired speed conditions. The speed conditions are mirrored for the opposite direction drive. The APT facility is shown in Figure 7. It is composed of a mobile loading unit and stationary equipment. The loading unit is set in a floating frame fixed within a solid sliding frame. The suspension is basically of the same principle as found on most freight vehicles. The motor, transmission, and breaking systems are all placed on the movable loading unit. Since the facility is in operation for some time, initiation and early operation phase of pavement performance model can be evaluated; the future pavement behaviour is extrapolated and updated as the experiment goes on.

4.2. Pavement Performance: Transversal Unevenness. Unevenness was ascertained from cross sections of pavement surface. The surface was scanned by a handheld Lidar laser scanner, high density point mesh was created with accuracy of $40 \mu \mathrm{m}$ (microns), and unevenness as small as $50 \mu \mathrm{m}$ could be evaluated exceeding by far the required preciseness. Preliminary evaluation could be made during the scan and creation of the point mesh. More elaborate processing was performed in the VXelements 2.0 software. Extracted cross section data were further evaluated in the MATLAB software. The resulting values are shown graphically in Figure 8.

The results can be deterministically evaluated and described by either linear or polynomic equation; see (5) and (6).
TABLE 6: APT facility technical parameters.

\begin{tabular}{lc}
\hline & Technical parameters \\
\hline Facility & Accelerated pavement testing facility \\
Construction & Semimobile, linear \\
Type & $105-03-01$ \\
Maximum velocity & $2.22 \mathrm{~m} \cdot \mathrm{s}^{-1}$ \\
Load & $57.5 \mathrm{kN}$ \\
Max acceleration & $2 \mathrm{~m} \cdot \mathrm{s}^{-2}$ \\
Max deceleration & $5 \mathrm{~m} \cdot \mathrm{s}^{-2}$ \\
Location & Indoor \\
Operational & $10-40^{\circ} \mathrm{C}$ \\
temperature & \\
Operational & \\
humidity & $30-80 \%$ without condensation \\
Engine power & $45 \mathrm{~kW}$ \\
Transition & $\mathrm{CLP} \mathrm{HC} \mathrm{VG} \mathrm{320,} \mathrm{MOBIL} \mathrm{SHC} \mathrm{GEAR} \mathrm{320}$ \\
Energy & $3+\mathrm{N}+\mathrm{PE}$, AC, $50 \mathrm{~Hz}, 230 / 400, \mathrm{~V}, \mathrm{TN}-\mathrm{S}$ \\
requirements &
\end{tabular}

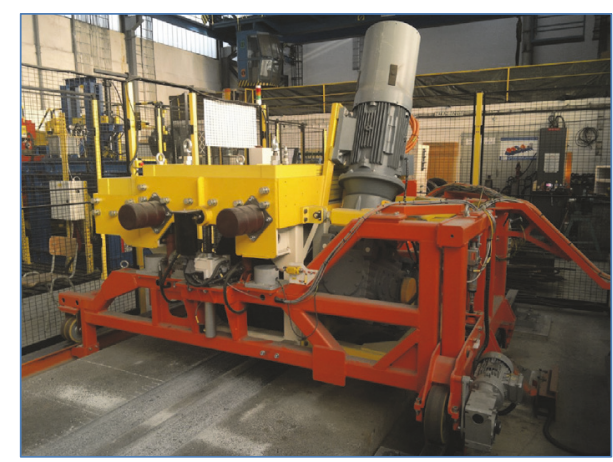

FIGURE 7: APT facility.

Linear equation:

$$
\begin{aligned}
y & =0.00001894 x-0.18071429 . \\
R^{2} & =0.95
\end{aligned}
$$

Polynomic 5th-degree equation:

$$
\begin{aligned}
y= & -6 E-25 x^{5}+2 E-19 x^{4}-3 E 14 x^{3}+1 E-9 x^{2} \\
& -3 E-6 x+0.0006 \\
R^{2}= & 0.9999 .
\end{aligned}
$$

4.3. Pavement Performance: Longitudinal Unevenness. The same approach as that for transversal unevenness was used for data collection and evaluation of longitudinal unevenness. The longitudinal unevenness is represented by International Roughness Index (IRI) with unit $\mathrm{m} \cdot \mathrm{km}^{-1}$ [28].

IRI was evaluated in accordance with Reference Quarter Car Simulation Model; the values lie within interval $3.3-6.81 \mathrm{~m} \cdot \mathrm{km}^{-1}$; however, these values are somewhat skewed 


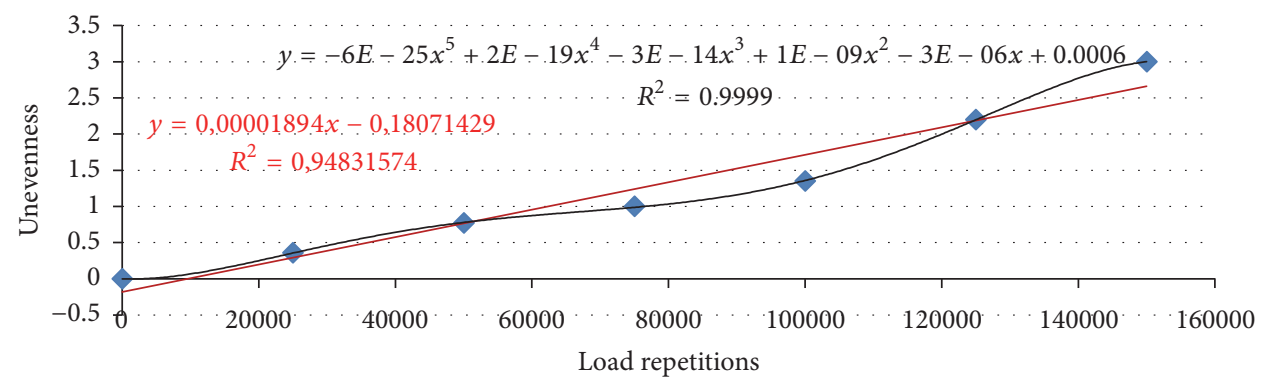

FIgURE 8: Transversal unevenness on the experimental pavement section.

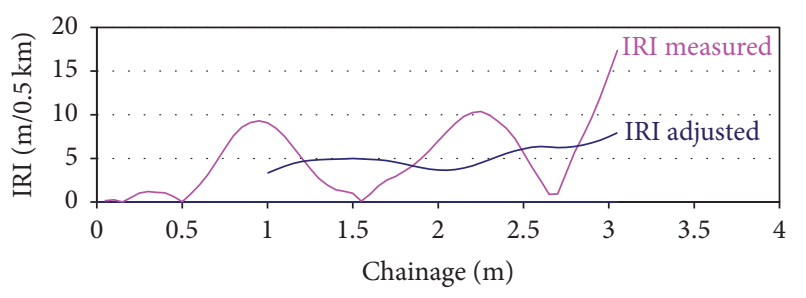

FIgURE 9: IRI evaluation.

since they incorporate outermost pavement stretches where the loading unit is in a standstill. After we adjust the IRI by exclusion of these local extremes, the interval for the constant speed stretch of the pavement is much more prudent, $3.3-3.9 \mathrm{~m} \cdot \mathrm{km}^{-1}$. The longitudinal unevenness can be seen in Figure 9.

Pavement performance model used for optimization of overlay design was a result of APT pavement performance described in this section and long term pavement performance monitoring of real pavement section in operation. The pavement performance model is a cubic polynomial function described by

$y$

$$
\begin{array}{r}
=0,000327396322 x^{3}+0,019659276067 x^{2} \\
-0,101539268713 x+1,605597316821
\end{array}
$$

coefficient of determination $R^{2}=0,864836$.

This function is used to predict pavement performance (as IRI development) over time, that is, traffic loading. IRI in a particular year is used to estimate annual road user costs. As seen in Section 5, these costs do not enter the overlay design calculation itself but are pivotal when evaluating the timing of said overlay.

\section{Optimization of Rehabilitation Planning}

Optimizing of decision-making process in rehabilitation planning is based on the LCCA principles. The gist of the optimization is to perform CBA for each rehabilitation scenario and subsequent calculation and comparison of optimization index of those scenarios.
5.1. Cost Benefit Analysis. CBA compares the cash flows of "do nothing" scenario and "do something" scenario. As a result, economic benefits gained through rehabilitation can be compared with financial costs for applied rehabilitation technologies. Combination of three economic indicators is used to evaluate the economic viability of each scenario; the indicators are the payback period, internal rate of return, and the net present value. Monetization of socioeconomic costs and benefits from pavements with rehabilitated ACM surfacing, respectively, are crucial for ascertainment of economic indicators. The benefits are related to difference in pavement quality in scenario without rehabilitation and scenario with rehabilitation. Benefits can be internal and external. In this case study, we used internal benefits which include road user operation costs and travel time costs as these can be monetized using World Bank's endorsed method. The external benefits including environmental savings and macroeconomic implications are omitted as all available monetization methods were considered by road administration authorities as subjective, that is, not reliable.

Overall road user benefits based on proposed rehabilitation technology and its investment costs, road administrator's costs, timing of rehabilitation, and discount rate can be calculated according to

$$
\mathrm{RUB}=\sum_{t=1}^{z}\left[\left(\mathrm{RUC}_{\mathrm{DS}}-\mathrm{RUC}_{\mathrm{DN}}\right) \cdot k_{\mathrm{DEG}} \cdot k_{\mathrm{ATG}}\right]_{t},
$$

where

RUB are road user benefits $[€]$,

$\mathrm{RUC}_{\mathrm{DS}}$ are road user costs in "do something" variant $[€]$,

RUC $_{\mathrm{DN}}$ are road user costs in "do nothing" variant $[€]$,

$k_{\mathrm{DEG}}$ is coefficient of function predicting condition of the pavement,

$k_{\mathrm{ATG}}$ is annual transportation growth coefficient.

Pavement performance model described in previous sections enters the overlay optimization model in the calculation of road user benefits in the form of $k_{\mathrm{DEG}}$ coefficient. As the pavement performance drops (represented as an increase of IRI), road user costs rise, respectively, as a result of increased needs 
TABLE 7: Life cycle cost analysis and cost benefit analysis.

\begin{tabular}{|c|c|c|c|c|c|}
\hline Variant & Variant scenario & $\begin{array}{c}\text { Rehabilitation 5th } \\
\text { year }\end{array}$ & $\begin{array}{c}\text { Rehabilitation 10th } \\
\text { year }\end{array}$ & $\begin{array}{l}\text { Rehabilitation } 15 \text { th } \\
\text { year }\end{array}$ & $\begin{array}{c}\text { Rehabilitation 20th } \\
\text { year }\end{array}$ \\
\hline Rehabilitation action & - & $\begin{array}{l}\text { Overlay } \\
36 \mathrm{~mm} \\
\end{array}$ & $\begin{array}{c}\text { Overlay } \\
52 \mathrm{~mm} \\
\end{array}$ & $\begin{array}{l}\text { Overlay } \\
62 \mathrm{~mm} \\
\end{array}$ & $\begin{array}{c}\text { Overlay } \\
71 \mathrm{~mm} \\
\end{array}$ \\
\hline Investment cost & $0 €$ & $69,084 €$ & $99,788 €$ & $118,978 €$ & $136,249 €$ \\
\hline Maintenance cost & $846,938 €$ & $858,066 €$ & $941,350 €$ & $1,162,456 €$ & $1,581,330 €$ \\
\hline Road agency cost & $846,938 €$ & $927,150 €$ & $1,041,138 €$ & $1,281,434 €$ & $1,717,579 €$ \\
\hline \multicolumn{6}{|l|}{ Road user costs } \\
\hline Vehicle operating cost & $8,316,431 €$ & $9,995,382 €$ & $11,689,165 €$ & $13,594,956 €$ & $16,045,362 €$ \\
\hline Travel time cost & $822,241 €$ & $973,891 €$ & $1,125,826 €$ & $1,290,801 €$ & $1,569,194 €$ \\
\hline Total road user cost & $9,138,673 €$ & $10,969,273 €$ & $12,814,991 €$ & $14,885,757 €$ & $17,614,555 €$ \\
\hline Life cycle length & 20 & 25 & 30 & 35 & 40 \\
\hline \multicolumn{6}{|l|}{$\mathrm{CBA}$} \\
\hline NPV & - & $20,333 €$ & $26,739 €$ & $14,527 €$ & $1,438 €$ \\
\hline IRR & - & $48.30 \%$ & $155.10 \%$ & $139.40 \%$ & $99.50 \%$ \\
\hline $\mathrm{PP}$ & - & 6 & 11 & 15 & 20 \\
\hline
\end{tabular}

for vehicle maintenance (lubricant, parts, service hours, etc.) and, at higher level of pavement damage, increased travel time costs stemming from drop of vehicle operating speeds. Since the pavement performance model allows ex ante ascertaining pavement deterioration, the same holds true for $k_{\mathrm{DEG}}$; that is, $k_{\mathrm{DEG}}$ can be ascertained for every year of pavement's life cycle. The coefficient is usually expressed as a unitless number, usually a ratio of RUC for pavement in perfect condition; for instance, at IRI $4.0 \mathrm{~m} \cdot \mathrm{km}^{-1} k_{\mathrm{DEG}}=1.2$ denotes a $20 \%$ increase of road user costs for vehicles traveling on this particular damaged pavement as opposed to the situation when the pavement would be in a perfect condition with IRI $0.0 \mathrm{~m} \cdot \mathrm{km}^{-1}$. Particular $k_{\mathrm{DEG}}$ values related to pavement performance model need to be based either on credible road international management software solutions such as HDM4 or RoSy or on a national solution based on empirical evidence.

5.2. Optimization Index. Optimization index is basically a unitless number calculated as division of all life cycle costs and extension of the original life cycle span.

$$
\mathrm{OI}=\frac{\left(\mathrm{RC}+\mathrm{MC}_{\mathrm{BR}}+\mathrm{MC}_{\mathrm{AR}}+\mathrm{UC}_{\mathrm{BR}}+\mathrm{UC}_{\mathrm{AR}}\right)}{T t},
$$

where

OI is optimization index,

$\mathrm{RC}$ are rehabilitation costs $[€]$,

$\mathrm{MC}_{\mathrm{BR}}$ are maintenance costs before rehabilitation [€],

$\mathrm{MC}_{\mathrm{AR}}$ are maintenance costs after rehabilitation [€],

$\mathrm{UC}_{\mathrm{BR}}$ is sum of user costs before rehabilitation [€],

$\mathrm{UC}_{\mathrm{AR}}$ is sum of user costs after rehabilitation [€],

$\mathrm{Tt}$ is number of years of extended service life.
TABLE 8: Calculation of optimization index.

\begin{tabular}{lccc}
\hline Scenario & $\begin{array}{c}\text { Sum of all life } \\
\text { cycle costs } \\
{[€]}\end{array}$ & $\begin{array}{c}\text { Extension of the } \\
\text { life cycle } \\
\text { [year] }\end{array}$ & $\begin{array}{c}\text { Optimization } \\
\text { index } \\
{[-]}\end{array}$ \\
\hline $\begin{array}{l}\text { No } \\
\text { rehabilitation }\end{array}$ & 846,938 & 0 & 0 \\
$\begin{array}{l}\text { Rehabilitation } \\
\text { in year 5 }\end{array}$ & 927,150 & 25 & 37,086 \\
$\begin{array}{l}\text { Rehabilitation } \\
\text { in year 10 } \\
\text { Rehabilitation } \\
\text { in year 15 } \\
\text { Rehabilitation } \\
\text { in year 20 }\end{array}$ & $1,041,138$ & 30 & 34,705 \\
\hline
\end{tabular}

Optimization in this case study is based on a calculation of described overlay design, pavement performance models, CBA, and optimization index. The calculation of optimization index itself is shown in Table 8; it is based on life cycle cost analysis in Table 7 . The results of Table 8 are graphically depicted in Figure 10. We can see that rehabilitation in year 10 scores the lowest OI and thus is optimal.

More diligent approach would call for the evaluation to be done in each year, not just in years 5, 10, 15, and 20. The result would be a refined curve of the same shape, with the possibility that the refinement could shift the optimal rehabilitation by a year or two. This is a question of due diligence of particular administrator and possibility of automating the calculation by Excel macro file or a software solution.

5.3. Sensitivity Analysis of Overlay Design and Timing Optimization. Sensitivity analysis shows the effect of input changes on the overall result of the optimization. In the analysis, one input parameter for the optimization is changed and 
TABLE 9: Elasticity analysis.

\begin{tabular}{|c|c|c|c|c|}
\hline Input & Original NPV & $\begin{array}{l}\text { NPV for } 1 \% \text { input } \\
\text { change }\end{array}$ & $\begin{array}{c}\text { Difference in } \\
\text { NPV }\end{array}$ & Elasticity \\
\hline $\begin{array}{l}\text { Roughness pavement } \\
\text { performance model }\end{array}$ & $573,502.33$ & $543,660.36$ & $15,642.52$ & $2.8 \%$ \\
\hline $\begin{array}{l}\text { Fatigue parameter change } \\
\text { ( } a, b \text { parameters })\end{array}$ & $573,502.33$ & $553,047.83$ & $6,255.05$ & $1.12 \%$ \\
\hline Resiliency of critical layer & $573,502.33$ & $553,047.83$ & $6,255.05$ & $1.12 \%$ \\
\hline
\end{tabular}

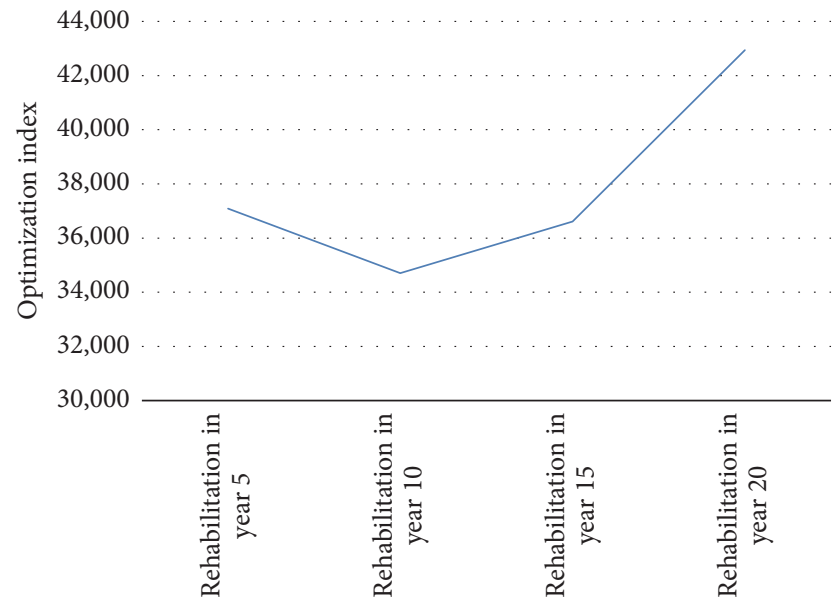

FIgURe 10: Optimization index.

the resulting aberrations in financial and economical parameters are presented. To evaluate elasticity of individual parameters, only one particular parameter can be tested at a time. Individual parameter is critical; that is, it has elasticity over $5 \%$, if a change of $1 \%$ in the parameter causes a shift in the result of $5 \%$. Elasticity analysis for this particular case study is shown in Table 9. Net present value of overlay variant was chosen to represent the result under observation as it represents the most important result for the road administrator. Input parameters for which sensitivity analysis was performed were

(i) roughness pavement performance model,

(ii) fatigue parameter change ( $a, b$ parameters),

(iii) resiliency of critical layer.

The analysis shows that neither of observed input parameters is critical by itself. However, their effects are synergetic and combination of flaws in these inputs can easily lead to unrealistic results. Therefore, the most precise definition of said inputs is required for optimization of overlay design and timing strategies.

\section{Conclusion}

The objective of this article was to elucidate on the methods for overlay design and creation of pavement performance model and decision-making method for identification of optimal rehabilitation time. This approach is very complex.
However, it can be adopted on national level with some effort, provided that the national research can supply or substitute the experimental part. The presented case study shows that the combination of pavement structure design methods, experimental fatigue tests of ACM, experimental pavement testing, and/or long term pavement performance monitoring if combined with economic appraising of road user costs can be used to optimize overlay thickness and rehabilitation timing. Additional data is required, namely, traffic data and climatic data of given region. The critical point of similar methodologies is usually the creation of pavement performance models. APT data backed by long term performance monitoring as described in this article seems to be preferable when creating pavement performance models. Downside of this approach is that the test needs to be performed for particular pavement type, which can take time as the data may not be readily available. The pavement performance model can be then employed for all pavements with ACM surfacing within given traffic load class, as these are not expected to differ significantly. Sensitivity analysis evaluates input parameters presented in the article that are needed for the overlay optimization. It shows impact of input changes on the overall result of the overlay scenario results. Preliminary results from this case study prove in practice that this approach is a good way to refine the decision-making process of rehabilitation planning which leads to increase in socioeconomic benefits for the public and at the same time helps to decrease capital cost of road administration.

\section{Conflicts of Interest}

The authors declare that there are no conflicts of interest regarding the publication of this paper.

\section{Acknowledgments}

This paper is the result of the project implementation "Independent Research of Civil Engineering Construction for Increase in Construction Elements Effectiveness" (ITMS: 26220220112) supported by the Research \& Development Operational Programme funded by the ERDF.

\section{References}

[1] A. Loulizi, I. L. Al-Qadi, and M. Elseifi, "Difference between in situ flexible pavement measured and calculated stresses and strains," Journal of Transportation Engineering, vol. 132, no. 7, pp. 574-579, 2006. 
[2] B. Novotný and A. Hanuška, The Theory of Multi Layered Half Space, VEDA, Bratislava, Slovakia, 1983.

[3] J. Čelko and J. Komačka, "Analysis of the pavement bearing capacity on the deflection bowl basis," in Proceedings of the Fifth International Conference on the Bearing Capacity of Roads and Airfields, pp. 609-617, Trondheim, Norway, 1998.

[4] A. Maji and A. Das, "Reliability considerations of bituminous pavement design by mechanistic-empirical approach," International Journal of Pavement Engineering, vol. 9, no. 1, pp. 19-31, 2008.

[5] M. Sanchez-Silva, O. Arroyo, M. Junca, S. Caro, and B. Caicedo, "Reliability based design optimization of asphalt pavements," International Journal of Pavement Engineering, vol. 6, no. 4, pp. 281-294, 2005.

[6] European Committee for Standardization (CEN), "Bituminous mixtures-Test method for hot mix asphalt-Part 24: resistant to fatigue," EN 12697-24, Brussels, 2003.

[7] European Committee for Standardization (CEN), "Bituminous mixtures-Test method for hot mix asphalt-Part 26: complex modulus," EN 12697-26, Belgium, 2003.

[8] Technical Standard TP 170, "Pavement Design for roads," Ministry of Transportation of the Czech Republic, Prague, 2004.

[9] J. Mikolaj, Ĺ. Remek, and M. Kozel, "Life cycle extension of a pavement structure," Communications, vol. 18, no. 4, pp. 83-89, 2016.

[10] F. Schlosser, E. Šrámeková, and J. Šrámek, "Rheology, deformational properties and fatigue of the asphalt mixtures," Advanced Materials Research, vol. 875-877, pp. 578-583, 2014.

[11] A. Ferreira, L. D. Picado-Santos, Z. Wu, and G. Flintsch, "Selection of pavement performance models for use in the Portuguese PMS," International Journal of Pavement Engineering, vol. 12, no. 1, pp. 87-97, 2011.

[12] J. Yu, E. Y. Chou, and Z. Luo, "Development of linear mixed effects models for predicting individual pavement conditions," Journal of Transportation Engineering, vol. 133, no. 6, pp. 347354, 2007.

[13] A. Gupta, P. Kumar, and R. Rastogi, "Critical review of flexible pavement performance models," KSCE Journal of Civil Engineering, vol. 18, no. 1, pp. 142-148, 2014.

[14] H. P. Hong and S. S. Wang, "Stochastic modeling of pavement performance," The International Journal of Pavement Engineering, vol. 4, no. 4, pp. 235-243, 2003.

[15] E. Oscarsson, "Evaluation of the Mechanistic-Empirical Pavement Design Guide model for permanent deformations in asphalt concrete," International Journal of Pavement Engineering, vol. 12, no. 1, pp. 1-12, 2011.

[16] World Road Association (PIARC), "Highway performance monitoring systems," Technical Committee 6 Road Management, ISBN 2-84060-052-8, P. 68, 1997.

[17] Industrial Property Office of Sr, "Accelerated Pavement Testing facility: tester 105-03-01," Design Patent 7396, PÚV 65-2016, Banská Bystrica, 2016.

[18] A. Chytčáková, Evaluation Parameters of Operational Competence in the Pavement Management System [Ph.D. thesis], University of Žilina, Žilina, Slovakia, 2014.

[19] G.-F. Peng, Y.-Z. Huang, H.-S. Wang, J.-F. Zhang, and Q.B. Liu, "Mechanical properties of recycled aggregate concrete at low and high water/binder ratios," Materials Science and Engineering, vol. 2013, Article ID 842929, 6 pages, 2013.

[20] S. Labi and K. C. Sinha, "Life-cycle evaluation of flexible pavement preventive maintenance," Journal of Transportation Engineering, vol. 131, no. 10, pp. 744-751, 2005.
[21] Z. Li and S. Madanu, "Highway project level life-cycle benefit/cost analysis under certainty, risk, and uncertainty: Methodology with case study, Journal of Transportation Engineering, vol. 135, no. 8, pp. 516-526, 2009.

[22] V. Mandapaka, I. Basheer, S. Khushminder, P. Udloitz, J. T. Harvey, and N. Sivaneswaran, "Mechanistic-empirical and life-cycle cost analysis for optimizing flexible pavement maintenance and rehabilitation," Journal of Transportation Engineering, vol. 138, no. 5, 2012.

[23] J. Santos and A. Ferreira, "Life-cycle cost analysis system for pavement management at project level," International Journal of Pavement Engineering, vol. 14, no. 1, pp. 71-84, 2013.

[24] U.S. Department od Transportation, "Life-Cycle Cost Analysis in Pavement Design," Federal Highway Administration, 1998, No. FHWA-SA-98-079.

[25] I. Gschwendt, "Pavement structure design," Technical Standards 3/2009, Ministry of Transport and Telecommunication, Slovakia.

[26] M. Kozel, The Application of the Decision Methods PMS [Ph.D. thesis], University of Zilina, Zilina, Slovakia, 2016.

[27] H. Y. Katman, M. R. Ibrahim, M. R. Karim, N. S. Mashaan, and S. Koting, "Evaluation of permanent deformation of unmodified and rubber-reinforced SMA asphalt mixtures using dynamic creep test," Advances in Materials Science and Engineering, vol. 2015, Article ID 247149, 11 pages, 2015.

[28] J. Čelko, M. Decký, and M. Kováč, “An analysis of vehicle - road surface interaction for classification of IRI in frame of Slovak PMS," in Maintenance and Reliability, vol. 1, pp. 15-21, Polish Maintenance Society, Warszawa, Poland, 2009. 

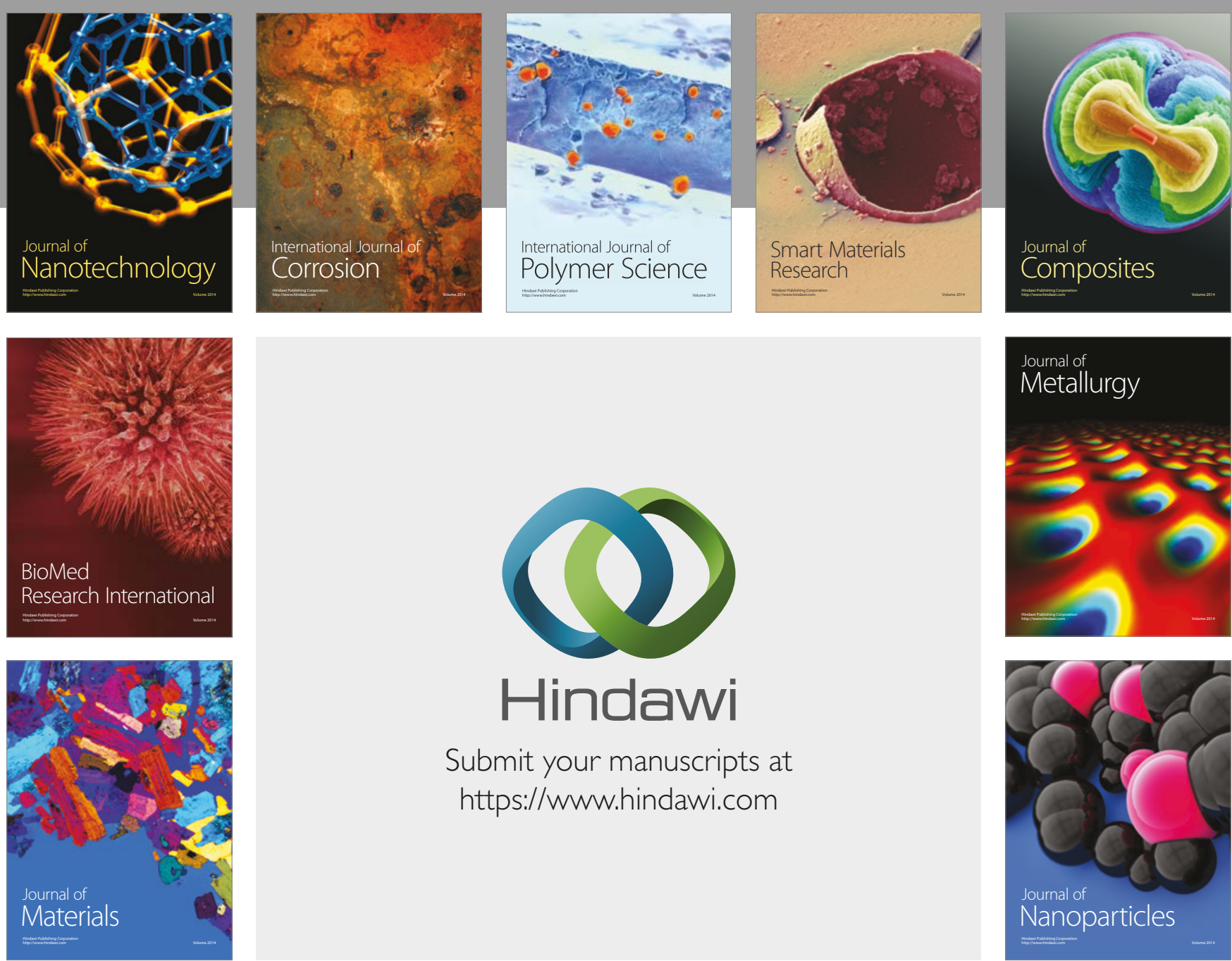

\section{Hindawi}

Submit your manuscripts at

https://www.hindawi.com
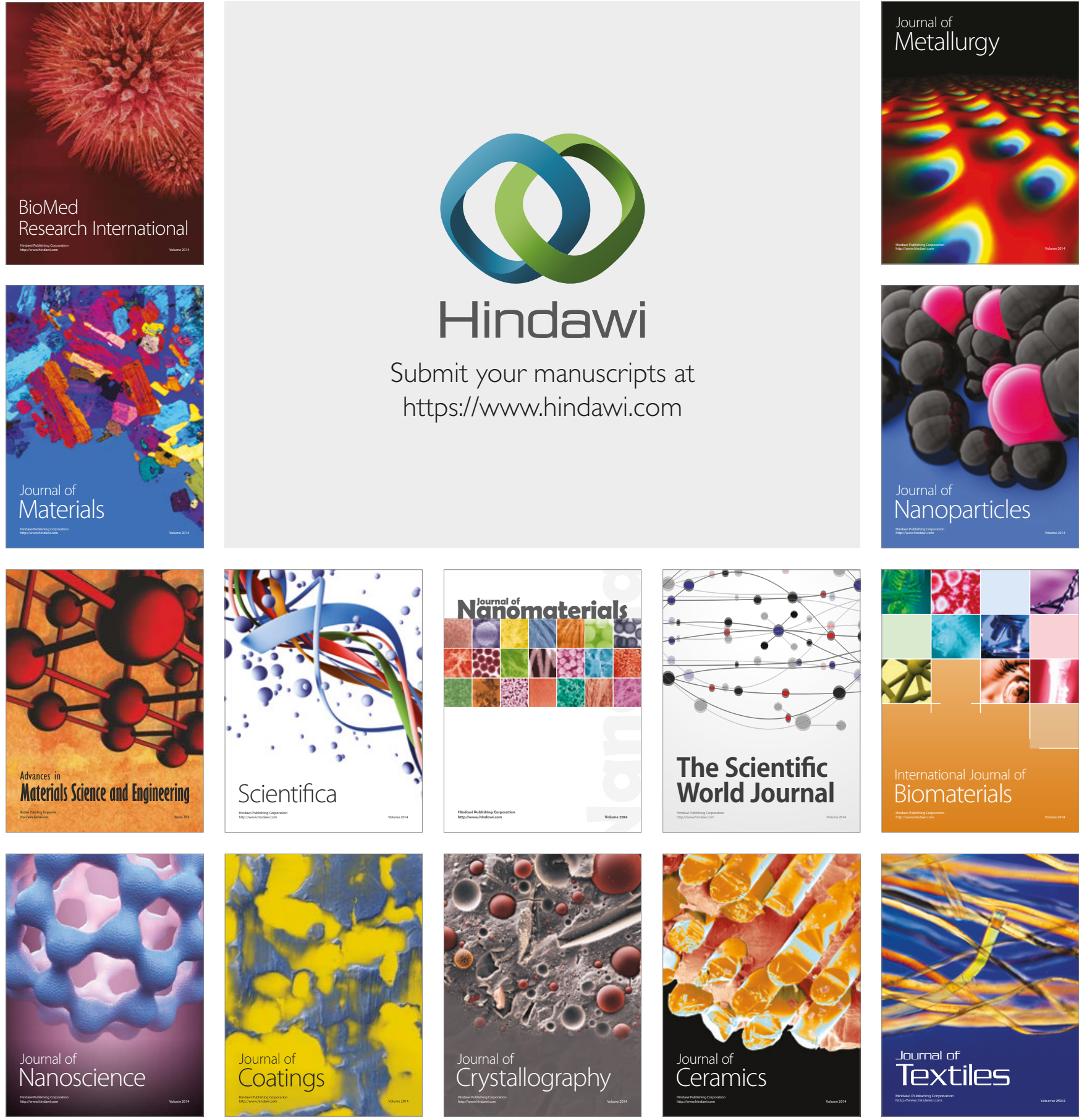

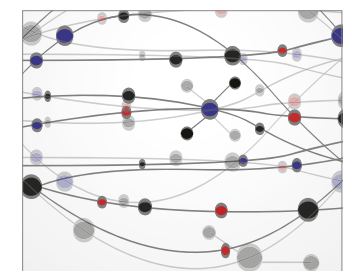

The Scientific World Journal
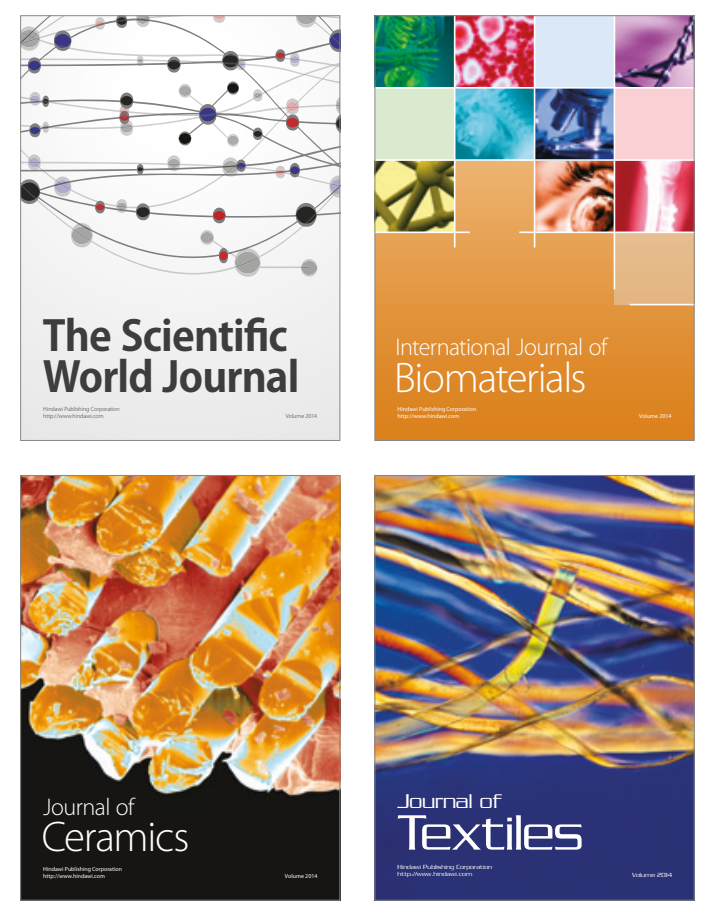